\title{
Description of Culicoides (Culicoides) bysta n. sp., a new member of the Pulicaris group (Diptera: Ceratopogonidae) from Slovakia
}

\author{
Adela Sarvašová ${ }^{\prime}$ Alica Kočišovál ${ }^{*}$, Ermanno Candolfi, ${ }^{2,3}$ and Bruno Mathieu²
}

\begin{abstract}
Background: Species of the genus Culicoides Latreille, 1809 (Diptera: Ceratopogonidae) are mainly known as vectors of arboviruses such as bluetongue (BTV) and Schmallenberg (SBV). Among the known vectors, few species within the subgenus Culicoides Latreille, 1809 have been implicated in the transmission of BTV and SBV. Nevertheless, phylogenetic studies had revealed the presence of cryptic and undescribed species in Europe, raising questions about their vectorial role. A previous integrative study, associating morphology and barcode data, raised the hypothesis of the presence of undescribed species in Slovakia. The present study, combining morphological and molecular approaches, is aimed to support the hypothesis and a description of Culicoides bysta n. sp. is provided.

Methods: Series of male and female specimens were dissected and several of them were sequenced for the barcode region of the mitochondrial cytochrome c oxidase subunit 1 gene (cox1). Bayesian inference phylogenetic analyses based on 72 cox 1 sequences of the species belonging to the Pulicaris group of the subgenus Culicoides, were carried out and the frequencies of intra/interspecific variations were analyzed. The morphology of abundant material of the new species (31 females and 12 males) was examined and compared with the paratypes of Culicoides boyi Nielsen, Kristensen \& Pape, 2015 and with specimens of Culicoides pulicaris Linnaeus, 1758. For females, suture distances on the eyes were newly evaluated as a diagnostic character and for males we assessed a new measurement on the ninth tergite and on the apicolateral processes.

Results: Both phylogenetic analysis and barcode distances supported the distinct status of the new species, Culicoides bysta $n$. sp. described as a member of the Pulicaris group based on the morphology of males and females. The new species is closely related to C. boyi and C. pulicaris but can be distinguished on the basis of the wing pattern and the ratio between the two eye sutures. Both newly evaluated characters, i.e. eyes in females and male genitalia appeared to be diagnostic for distinguishing the new species described herein.
\end{abstract}

Conclusions: The vector potential of the recently described species C. boyi and C. bysta n. sp. to transmit arboviruses, such as BTV and SBV, is unknown. When considering these two species as being close to C. pulicaris, the previous data, such as the vector implication for C. pulicaris in BTV transmission, should be revaluated in future.

Keywords: Culicoides, Pulicaris group, DNA barcodes, New species description, Culicoides bysta n. sp.

\footnotetext{
* Correspondence: alica.kocisova@uvlf.sk

1 Department of Parasitology, University of Veterinary Medicine and Pharmacy

in Košice, Komenského 73, SK-04181 Košice, Slovak Republic

Full list of author information is available at the end of the article
}

\section{Biomed Central}

(c) The Author(s). 2017 Open Access This article is distributed under the terms of the Creative Commons Attribution 4.0 International License (http://creativecommons.org/licenses/by/4.0/), which permits unrestricted use, distribution, and reproduction in any medium, provided you give appropriate credit to the original author(s) and the source, provide a link to the Creative Commons license, and indicate if changes were made. The Creative Commons Public Domain Dedication waiver (http://creativecommons.org/publicdomain/zero/1.0/) applies to the data made available in this article, unless otherwise stated. 


\section{Background}

The biting midges of the genus Culicoides Latreille, 1809 (Diptera: Ceratopognidae) are small hematophagous insects. The biodiversity of this genus represented more than 1300 species worldwide [1] including some species implicated as vectors of arboviruses. In Europe, the species belonging to the subgenera Avaritia Fox, 1955 and Culicoides have been pointed out as potential vectors, at various levels, of the Bluetongue virus (BTV): C. (Avaritia) obsoletus (Meigen, 1818)/ C. (A.) scoticus Downes \& Kettle, 1952; C. (A.) dewulfi Goetghebuer, 1936; C. (A.) chiopterus (Meigen, 1830); C. (A.) imicola Kieffer, 1913; C. (Culicoides) pulicaris (L.); and C. (C.) lupicaris Downes \& Kettle, 1952 [2-10]. Within the subgenus Culicoides, C. (C.) punctatus (Meigen, 1804), a species close to C. pulicaris, has recently been mentioned as participating in the transmission of the Schmallenberg virus [11].

The exact number of species belonging to the subgenus Culicoides in the Palaearctic region is unknown, as different authors include different species in the subgenus [12]. Other authors presented their disagreement regarding the subgeneric nomenclature and thus classified the species related to $C$. pulicaris as the species of the Pulicaris group [13] and eventually subgroups [14]. Regardless of the chosen classification, the species related to and "grouped" with C. pulicaris vary among the authors. In an attempt to clarify the classification and the identification of the species within the Pulicaris group, phylogenetic studies based on cox 1 mitochondrial gene sequences [15-19], as well as on ITS2 rDNA region $[12,20]$, revealed the presence of cryptic species. Following the discovery of this genetic diversity, in 2013, a new species, C. paradoxalis Ramilo \& Delécolle, 2013, close to C. lupicaris was described from France and Portugal [21]. In Denmark, three species molecularly characterised in 2011 [18], have been recently described as new species, i.e. C. boyi, C. selandicus Nielsen, Kristensen \& Pape, 2015 and C. kalix Nielsen, Kristensen \& Pape, 2015 [18, 22]. It is worth to mention that for the four above mentioned recently described species, i.e. the one from Portugal and the three from Denmark, morphological studies have highlighted the diagnostic characters for accurate identification [21-23]. In the light of the cryptic diversity detected in this group, further undescribed species may be expected [15, 17, 19]. Further studies, including morphological exploration, are still required to eventually lead to the formal description of new species. Currently, new species are frequently discovered by both genetic discrepancies detected by barcode analyses (cox 1 region) and the presence of highly supported clade from phylogenetic studies [21, 22]. Besides, morphological studies are highly recommended to be linked to these genetic studies, for a better understanding of the composition of subgenus Culicoides [19].
In the present study, we describe a member of the Pulicaris group, $C$. (Culicoides) bysta $\mathrm{n}$. sp. The sample consisting of a unique female specimen found in our previous study [19] is now completed with a larger series of males and females. To support the distinct species status of the new species, we implemented a combination of morphological and phylogenetic (based on cox 1 gene) approaches.

\section{Methods \\ Sampling and identification of Culicoides}

Specimens used in this study were collected at 3 permanent trapping sites in eastern Slovakia (game park in Rozhanovce and cattle farms in Michalany and Tulcik), where the CDC miniature light trap model 1212 (John Hock Company, USA) was operated weekly, from April to November 2011-2015. In addition, occasional collections were done across Slovakia: Bysta (game park), Pcoline (cattle farm), Velaty (farm with different animals), Antalka (family house with animals), Ziar (family weekend house with sheep). The collection and identification procedures were described in the previous paper [19]. Specimens from Bulgaria, Kosovo, and Denmark were collected and identified within the VectorNet project, whereas the ones from France were from the French surveillance network funded by the French Ministry.

Morphological terminology follows Mathieu et al. [24] and Sarvašová et al. [19]. The antennal trichodea ratio (AtR), described by Meiswinkel [25], was measured for females to evaluate its diagnostic potential within the Pulicaris group. The ratio of the third segment, calculated by dividing the length of the first flagellomere by its width, previously evaluated by Nielsen et al. [22], was measured for females. On the eyes we investigated the usefulness of the new characters illustrated in Fig. 1. The length of the inter-ocular suture of the joined eyes (Lios) and the distance between the latter and the transverse suture above the first inter-ocular seta (Dios-ts) were measured. Subsequently, we computed the ratio consisting in Lios divided by Dios-ts; the length of the transverse suture was also reported (Lts). In order to discriminate males from the Pulicaris group, new morphological characters of aedeagus were measured and analyzed (Fig. 2): the length (Lap) and width (Wap) of the apical processes of the ninth tergite, the distance separating the two tips of the apical processes $(\mathrm{Dt})$, and the distance separating the base of the two apical processes $(\mathrm{Db})$. All measurements are in micrometres and are provided as the mean followed by the range (minimum-maximum) and the number of measurements in parentheses. The difference between measurements was determined by Mann-Whitney test $(P<0.05)$ using $\mathrm{R}$ software [26]. Characters measured for more than two 


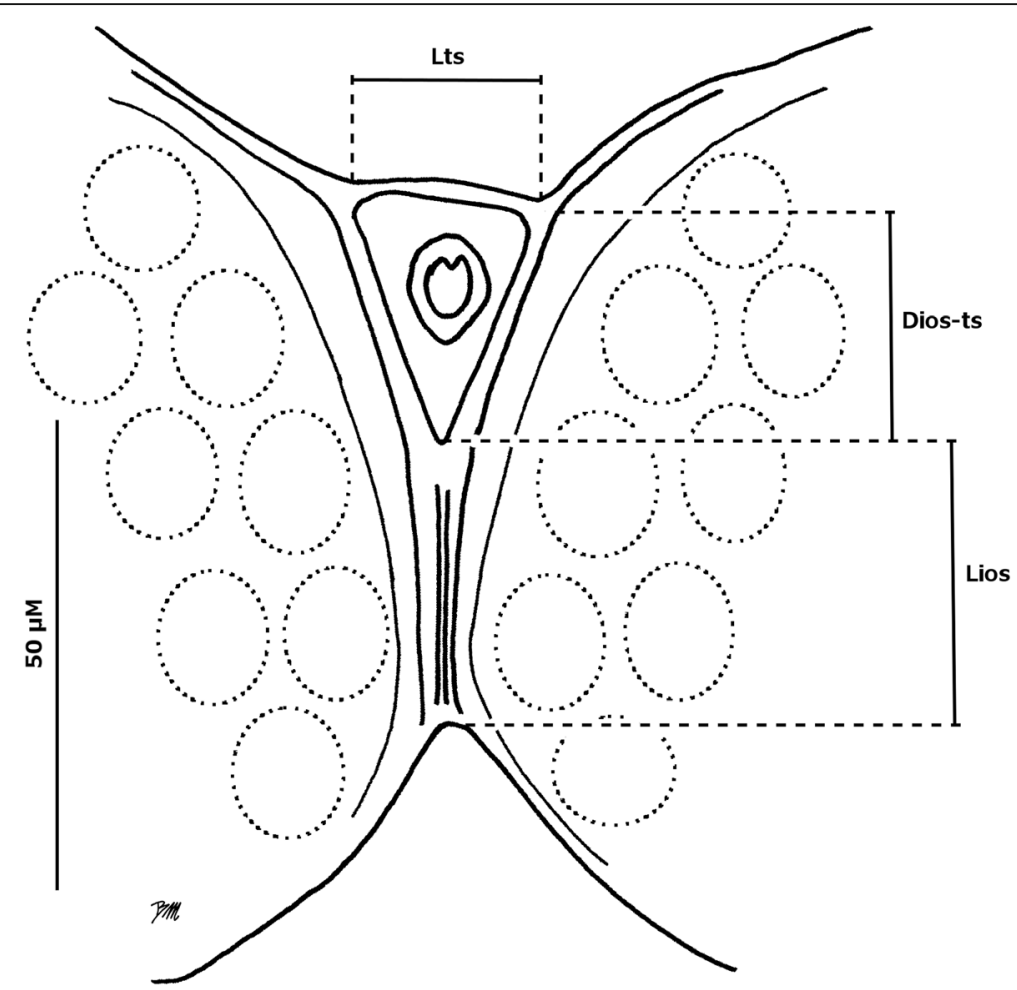

Fig. 1 Schematic illustration of joined eyes of a Culicoides spp. female, showing the measurements. Abbreviations: Lios, length of the inter-ocular suture; Lts, length of the transverse suture; Dios-ts, distance between the inter-ocular suture and the transverse suture

groups were tested by Kruskal-Wallis rank sum test prior to Mann-Whitney.

The holotype and 10 paratypes are deposited in the collection of the Institut de Parasitologie et de Pathologie Tropicale de Strasbourg (IPPTS), 10 paratypes in the Slovak National Museum and 11 paratypes are deposited in the collection of the University of Veterinary Medicine and Pharmacy in Košice.

\section{DNA barcode and phylogenetics}

The following 53 cox 1 (mtDNA) sequences have been gathered from the Genbank: C. boyi (JF766293-96), C. bysta n. sp. (KJ624118) referred as speA in a previous study [19], C. kalix (JF766328-31), C. lupicaris (HQ 824431-33, KJ624097), C. newsteadi Austen GB (AM236 742-46), C. newsteadi N1 (GQ338915, KJ624101), C. newsteadi N2 (GQ338916-20), C. newsteadi N3

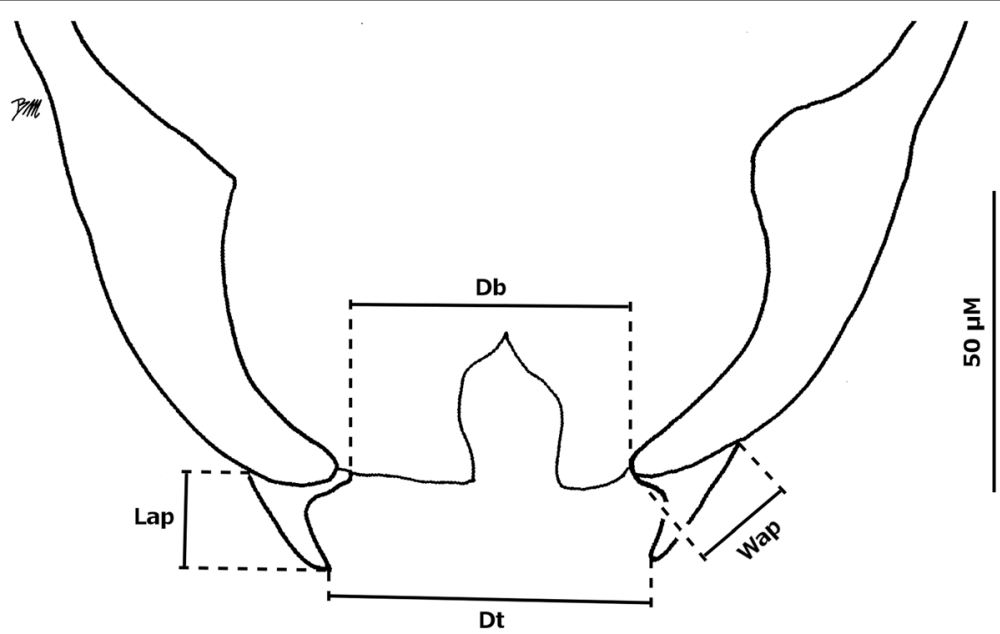

Fig. 2 Ninth tergite of male Culicoides spp. The measurements of the length (Lap) and the width (Wap) of the apical processes, the distance separating the two tips of the apical processes (Dt) and the distance between the bases of the two apical processes (Db) are shown 
(GQ338921-22, JF766322-23, JF766327), C. pulicaris P1 (AM236714-15, GQ338912-14, HQ824422-23, JF766363, JF766365, KJ624116-17), C. pulicaris P3 (GQ338910-11, KF591611), C. punctatus (JF766325-26, JF766356, JQ 620186-88, KJ624119), and C. selandicus (JF766320, JF 766324).

In addition, we extracted the DNA from thorax and first abdominal segments of 17 specimens of C. bysta $\mathrm{n}$. sp. and two C. boyi, using the DNeasy blood and tissue kit (Qiagen, USA). At the start of this study, barcoding fragments of the first 11 specimens have been amplified following the protocol of Pagès et al. [15] using the primers C1J1718/C1N2191 [27]. The resulting cox1 sequence size of $472 \mathrm{bp}$ is similar to the most $\operatorname{cox} 1$ sequences available for Culicoides species. To produce longer sized amplicons allowing more complete genetic studies, the cox 1 of the last 8 specimens have been amplified using the primer pairs LCO1490/HCO2198 [28] allowing a sequence size of up $687 \mathrm{bp}$. PCR products have been purified and sequenced by the Eurofins MWG Operon (Ebersberg, Germany). Information associating the origin and the accession number of the 19 newly sequenced specimens are presented in Table 1.

The 72 above mentioned cox 1 sequences were aligned using the ClustalW [29] and genetic distances were computed using the Jukes-Cantor model of MEGA version 6 [30]. The best-fit model of nucleotide substitutions was calculated as HKY $+\mathrm{I}+\Gamma$ by the JModelTest v.2.1.4 [31].
The latter model was used to parameterise a phylogenetic analysis carried out under the Bayesian Inference (1,000,000 generations), using the MrBayes v3.1.2 [32]. Two-thousand and five-hundreds of the saved trees were discarded and the remaining 7500 trees were used to construct the phylogenetic tree. Clade posterior probabilities (CPP) estimates were used to assess the robustness of tree nodes.

\section{Results \\ DNA barcode and phylogenetics}

The phylogenetic tree obtained by the Bayesian Inference is shown in Fig. 3. All specimens within the species and the cryptic species pointed out by previous authors $[15,22]$ are gathered into highly supported clades (CPP $=100 \%$ ). Three other nodes are quite well supported: (i) The node separating the three morphologically close species $C$. punctatus, $C$. kalix, and $C$. selandicus was well supported $(\mathrm{CPP}=94 \%)$; (ii) the two cryptic species $C$. pulicaris $\mathrm{P} 1-\mathrm{P} 3$ and C. lupicaris clustered into a clade supported by the $93 \%$ CPP; and (iii) a clade supported by the $92 \%$ CPP included C. newsteadi, C. newsteadi N3, C. bysta n. sp. and C. boyi. For each species, intra- and interspecific genetic distances are shown in Table 2. Culicoides newsteadi $\mathrm{N} 1$ and C. bysta $\mathrm{n}$. sp. showed a mean of intraspecific distances of 3.4 and $1.6 \%$, respectively. With the exception of the two latter species, all species have the mean of intraspecific distances lower

Table 1 Collection data for specimens of Culicoides bysta n. sp. and C. boyi used for genetic analyses

\begin{tabular}{|c|c|c|c|c|c|c|}
\hline GenBank ID ${ }^{a}$ & Species & Sex & Collection date & Country & Locality & Coordinates \\
\hline KY436038 & C. bysta n. sp. & $\mathrm{F}$ & 14 July 012 & Slovakia & Bysta & $48^{\circ} 31^{\prime} \mathrm{N}, 21^{\circ} 33^{\prime} \mathrm{E}$ \\
\hline KY436039 & C. bysta n. sp. & $\mathrm{F}$ & 11 May 2013 & Slovakia & Michalany & $48^{\circ} 30^{\prime} \mathrm{N}, 21^{\circ} 37^{\prime} \mathrm{E}$ \\
\hline KY436040 & C. bysta n. sp. & M & 8 August 2013 & Slovakia & Rozhanovce & $48^{\circ} 45^{\prime} \mathrm{N}, 21^{\circ} 21^{\prime} \mathrm{E}$ \\
\hline KY436041 & C. bysta n. sp. & M & 31 July 2013 & Slovakia & Rozhanovce & $48^{\circ} 45^{\prime} \mathrm{N}, 21^{\circ} 21^{\prime} \mathrm{E}$ \\
\hline KY436042 & C. bysta n. sp. & $\mathrm{F}$ & 26 June 2014 & Slovakia & Pčoline & $49^{\circ} 03^{\prime} \mathrm{N}, 22^{\circ} 10^{\prime} \mathrm{E}$ \\
\hline KY436043 & C. bysta n. sp. & $\mathrm{F}$ & 16 May 2013 & Slovakia & Tulcik & $49^{\circ} 5^{\prime} \mathrm{N}, 21^{\circ} 18^{\prime} \mathrm{E}$ \\
\hline KY436044 & C. bysta n. sp. & $\mathrm{F}$ & 19 June 2012 & France & Longeville-en-Barois & $48^{\circ} 44^{\prime} \mathrm{N}, 5^{\circ} 13^{\prime} \mathrm{E}$ \\
\hline KY436045 & C. bysta n. sp. & $\mathrm{F}$ & 19 June 2012 & France & Longeville-en-Barois & $48^{\circ} 44^{\prime} \mathrm{N}, 5^{\circ} 13^{\prime} \mathrm{E}$ \\
\hline KY436046 & C. bysta n. sp. & $\mathrm{F}$ & 19 June 2012 & France & Longeville-en-Barois & $48^{\circ} 44^{\prime} \mathrm{N}, 5^{\circ} 13^{\prime} \mathrm{E}$ \\
\hline KY436047 & C. bysta n. sp. & $\mathrm{F}$ & 19 June 2012 & France & Longeville-en-Barois & $48^{\circ} 44^{\prime} \mathrm{N}, 5^{\circ} 13^{\prime} \mathrm{E}$ \\
\hline KY436048 & C. bysta n. sp. & $\mathrm{F}$ & 19 June 2012 & France & Longeville-en-Barois & $48^{\circ} 44^{\prime} \mathrm{N}, 5^{\circ} 13^{\prime} \mathrm{E}$ \\
\hline KY436049 & C. bysta n. sp. & $\mathrm{F}$ & 26 June 2015 & France & Crastatt & $48^{\circ} 39^{\prime} \mathrm{N}, 7^{\circ} 25^{\prime} \mathrm{E}$ \\
\hline KY436050 & C. bysta n. sp. & $\mathrm{F}$ & 17 July 2015 & France & Jetterswiller & $48^{\circ} 40^{\prime} \mathrm{N}, 7^{\circ} 25^{\prime} \mathrm{E}$ \\
\hline KY436051 & C. bysta n. sp. & $\mathrm{F}$ & 25 June 2015 & France & Rangen & $48^{\circ} 40^{\prime} \mathrm{N}, 7^{\circ} 28^{\prime} \mathrm{E}$ \\
\hline KY436052 & C. bysta n. sp. & $\mathrm{F}$ & 21 August 2015 & Bulgaria & Muldava & $41^{\circ} 59^{\prime} \mathrm{N}, 24^{\circ} 56^{\prime} \mathrm{E}$ \\
\hline KY436053 & C. bysta n. sp. & $\mathrm{F}$ & 21 August 2015 & Bulgaria & Topolovo & $41^{\circ} 54^{\prime} \mathrm{N}, 25^{\circ} 01^{\prime} \mathrm{E}$ \\
\hline KY436054 & C. bysta n. sp. & $\mathrm{F}$ & 1 September 2015 & Kosovo & Stubel & $42^{\circ} 20^{\prime} \mathrm{N}, 21^{\circ} 27^{\prime} \mathrm{E}$ \\
\hline KY436055 & C. boyi & $\mathrm{F}$ & 26 June 2015 & Denmark & Zealand & $55^{\circ} 15^{\prime} \mathrm{N}, 12^{\circ} 01^{\prime} \mathrm{E}$ \\
\hline KY436056 & C. boyi & $\mathrm{F}$ & 26 June 2015 & Denmark & Zealand & $55^{\circ} 15^{\prime} \mathrm{N}, 12^{\circ} 01^{\prime} \mathrm{E}$ \\
\hline
\end{tabular}

${ }^{\mathrm{a} G e n B a n k}$ accession numbers refer to cytochrome $c$ oxydase 1 (cox1) sequences 


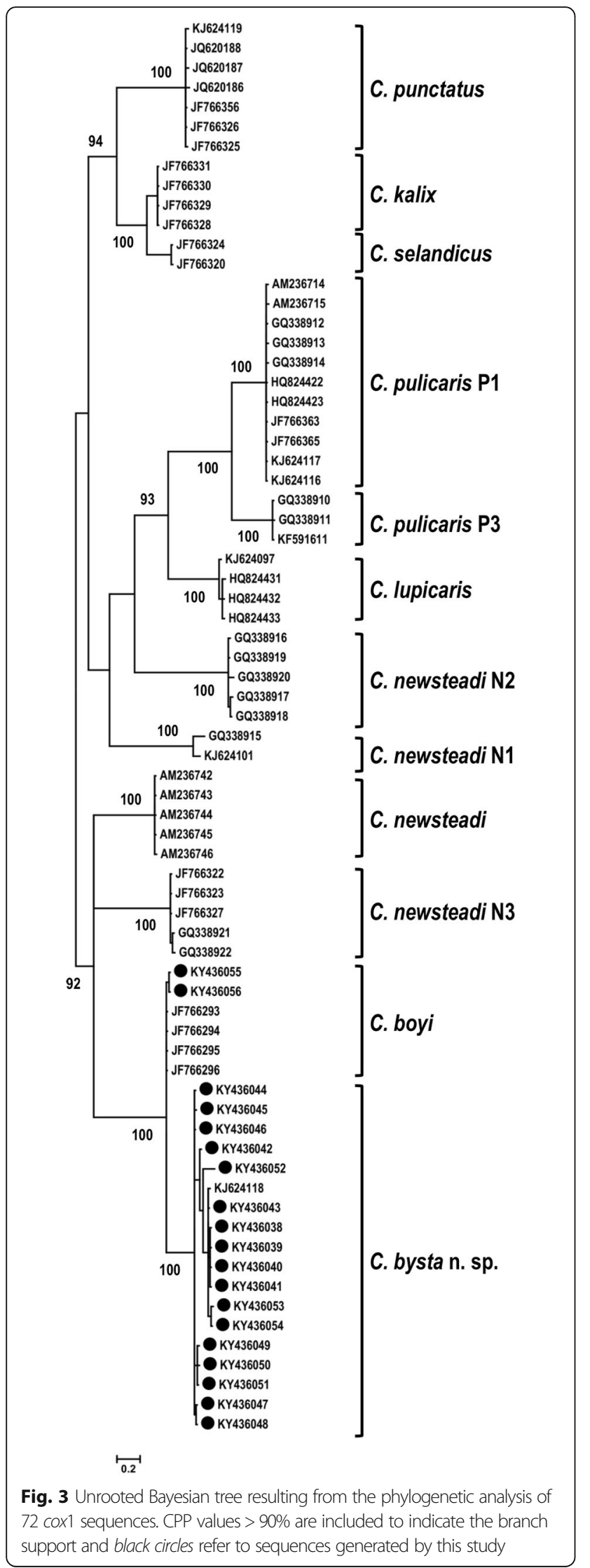

than $1 \%$. The minimum interspecific distances are the lowest between C. kalix/C. selandicus and C. bysta n. sp./C. boyi with 7.1 and $5.6 \%$, respectively. For all the other species, the minimum interspecific distances are higher than $11 \%$. Focusing on C. bysta n. sp. and C. boyi, pairwise distances are computed and frequencies are plotted by intra and interspecific variations (Fig. 4). No overlaps between the intraspecific distances (intra- $C$. boyi and intra-C. bysta n. sp.) and the interspecific distances were shown.

\section{Taxonomy}

Family Ceratopogonidae, Newman, 1834

Genus Culicoides Latreille, 1809

Subgenus Culicoides Latreille, 1809

Culicoides (Culicoides) bysta Sarvašová \& Mathieu n. sp. Syn. Culicoides sp. of Sarvašová et al. [19] (referred to as Culicoides speA)

Type-locality: Rozhanovce $\left(48^{\circ} 45^{\prime} \mathrm{N}, 21^{\circ} 21^{\prime} \mathrm{E}\right)$, Slovakia. Other localities: Slovakia - Antalka, $48^{\circ} 21^{\prime} \mathrm{N}, 19^{\circ} 56^{\prime} \mathrm{E}$, Bysta, $48^{\circ} 31^{\prime} \mathrm{N}, 21^{\circ} 33^{\prime} \mathrm{E}$, Michalany, $48^{\circ} 30^{\prime} \mathrm{N}, 21^{\circ} 37^{\prime} \mathrm{E}$, Pcoline, $49^{\circ} 03^{\prime} \mathrm{N} 22^{\circ} 10^{\prime} \mathrm{E}$, Tulcik, $49^{\circ} 5^{\prime} \mathrm{N}, 21^{\circ} 18^{\prime} \mathrm{E}$, France - Crastatt, $48^{\circ} 39^{\prime} \mathrm{N}, 7^{\circ} 25^{\prime} \mathrm{E}$, Jetterswiller, $48^{\circ} 40^{\prime} \mathrm{N}, 7^{\circ} 25^{\prime} \mathrm{E}$, Longeville-en-Barois, $48^{\circ} 44^{\prime} \mathrm{N}, 5^{\circ} 13^{\prime} \mathrm{E}$, Rangen, $48^{\circ} 40^{\prime} \mathrm{N}$, $7^{\circ} 28^{\prime} \mathrm{E}$, Bulgaria - Muldava, $41^{\circ} 59^{\prime} \mathrm{N}, 24^{\circ} 56^{\prime} \mathrm{E}$, Topolovo, $41^{\circ} 54^{\prime} \mathrm{N}, 25^{\circ} 01^{\prime} \mathrm{E}$, and Kosovo - Stubel, $42^{\circ} 20^{\prime} \mathrm{N}, 21^{\circ} 27^{\prime} \mathrm{E}$.

Type-material: The holotype and 10 paratypes (acc. no. IPPT-CL-2017-01 to IPPT-CL-2017-11) are deposited in the collection of the Institut de Parasitologie et de Pathologie Tropicale de Strasbourg (IPPTS), 10 paratypes (acc. no. SZ10896 to SZ10905) in the Slovak National Museum,

Table 2 Intra- and interspecific genetic distances computed using the Juke and Cantor model in MEGA. Minimum (Min) and Maximum (Max) distance values are presented as percentages

\begin{tabular}{|c|c|c|c|c|c|}
\hline \multirow[t]{2}{*}{ Species } & \multicolumn{3}{|c|}{ Intraspecific } & \multicolumn{2}{|c|}{ Interspecific } \\
\hline & Mean & Min & Max & Min & Max \\
\hline C. boyi & 0 & 0 & 0 & 5.6 & $23.9^{a}$ \\
\hline C. bysta n. sp. & 1.6 & 0 & 3.4 & 5.6 & $24.6^{a}$ \\
\hline C. kalix & 0 & 0 & 0 & 7.1 & 20.1 \\
\hline C. lupicaris & 0.5 & 0.5 & 0.5 & 15.2 & 22.1 \\
\hline C. newsteadi & 0.1 & 0 & 0.3 & 14.8 & 24.6 \\
\hline C. newsteadi N1 & 3.4 & 3.4 & 3.4 & 17.1 & 22.1 \\
\hline C. newsteadi N2 & 0.8 & 0.3 & 1.6 & 17.7 & 22.5 \\
\hline C. newsteadi N3 & 0.3 & 0 & 0.5 & 16.1 & 22.8 \\
\hline C. pulicaris P1 & 0.3 & 0 & 0.8 & 11.2 & 22.8 \\
\hline C. pulicaris P3 & 0.2 & 0 & 0.3 & 11.2 & 24.6 \\
\hline C. punctatus & 0.4 & 0 & 1 & 13.3 & 22.8 \\
\hline C. selandicus & 0.3 & 0.3 & 0.3 & 7.1 & 21.8 \\
\hline
\end{tabular}

${ }^{a}$ Maximum interspecific distance between C. bysta n. sp. and C. boyi is $7.6 \%$ 


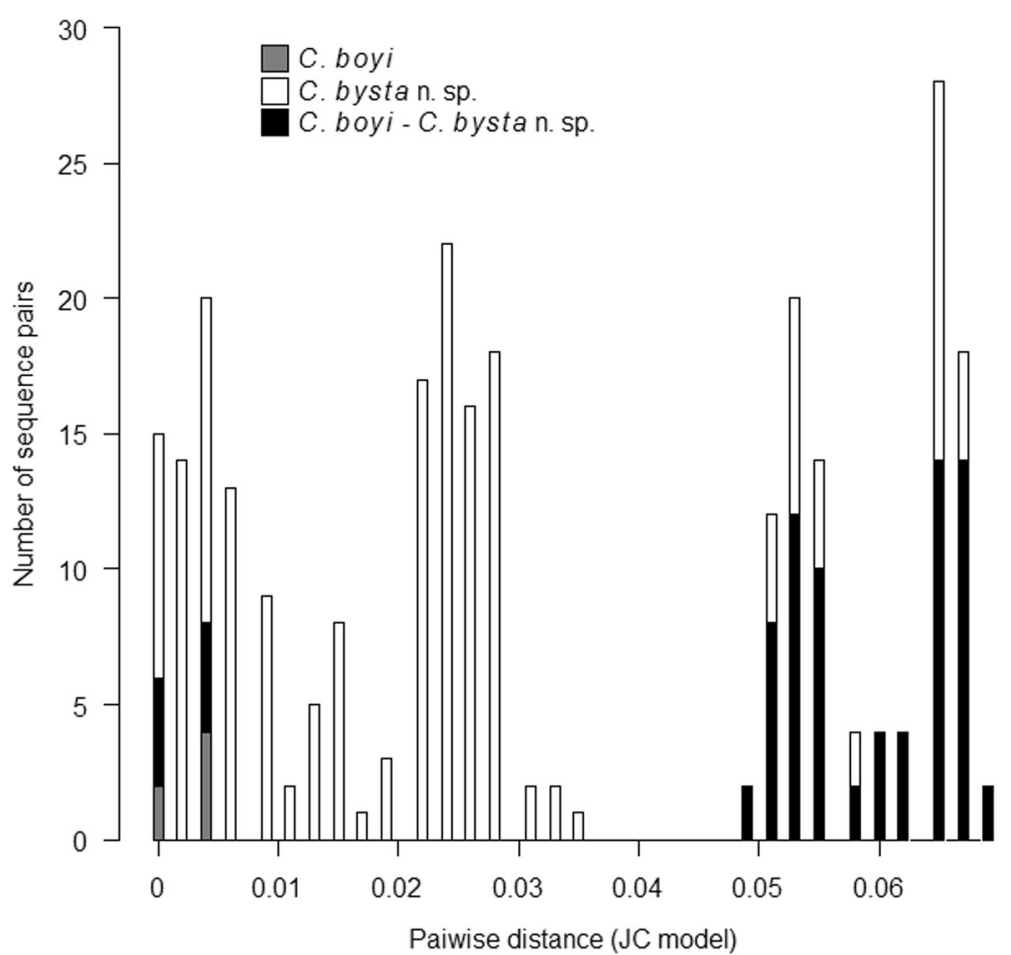

Fig. 4 Frequences of the pairwise distances showing intra- (grey and white) and interspecific (black) variations

and 11 paratypes (acc. no. UVLF-CL-2017-01 to UVLFCL-2017-11) are deposited in the collection of the University of Veterinary Medicine and Pharmacy in Košice as detailed below. Holotype male (IPPT-CL-201701): Slovakia: Rozhanovce, $48^{\circ} 45^{\prime} \mathrm{N}, 21^{\circ} 21^{\prime} \mathrm{E}, 11 . v i i .2013$. Paratypes: Slovakia: Antalka, $48^{\circ} 21^{\prime} \mathrm{N}, 19^{\circ} 56^{\prime} \mathrm{E}, 7 . v i .2014$ (1

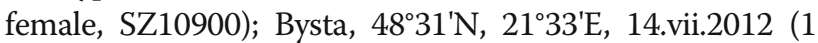
female,UVLF-2017-01), 28.vii.2012 (1 female, SZ10898); Michalany, $48^{\circ} 30^{\prime} \mathrm{N}, 21^{\circ} 37^{\prime} \mathrm{E}, 25 . \mathrm{v} .2011$ (1 female, SZ1 0897), 11.v.2013 (1 female;IPPT-CL-2017-03), 10.v.2014 (2 females, IPPT-CL-2017-04, IPPT-CL-08); Pcoline, 49 $03^{\prime} \mathrm{N}, 22^{\circ} 10^{\prime} \mathrm{E}, 26 . v i .2014$ (1 female, IPPT-CL-2017-02); Rozhanovce, $48^{\circ} 45^{\prime} \mathrm{N}, 21^{\circ} 21^{\prime} \mathrm{E}, \quad 8 . v .2013$ (4 females, SZ10899, UVLF-CL-2017-03, UVLF-CL-2017-05, UVLFCL-2017-06), 11.vi.2013 (1 male, UVLF-CL-2017-10), 31.vii.2013 (1 female, UVLF-CL-2017-02), 8.viii.2013 (1 male, IPPT-CL-2017-09), 31.vii.2013 (1 male, UVLFCL-2017-08), 13.viii.2013 (2 females; IPPT-CL-2017-07, UVLF-CL-2017-07), 11.v.2014 (1 male, UVLF-CL-201711), 3.ix.2014 (1 female, IPPT-CL-2017-05, 6 males, SZ10902, SZ10903, SZ10904, SZ905, IPPT-CL-201710, IPPT-CL-2017-11, UVLF-CL-2017-09), 21.viii.2014 (2 female, SNMxx, IPPT-CL-2017-06;); Tulcik, 495' N, $21^{\circ}$ 18'E, 16.v.2013 (3 females; SZ10896, SZ10901, UVLF-CL2017-04).

Non-type material examined: France: Crastatt, $48^{\circ}$ $39^{\prime} \mathrm{N}, 7^{\circ} 25^{\prime} \mathrm{E}, 26 . v i .2015$ (1 female); Jetterswiller, $48^{\circ} 40^{\prime} \mathrm{N}$, $7^{\circ} 25^{\prime} \mathrm{E}, 17 . v i i .2015$ (1 female); Longeville-en-Barois, $48^{\circ}$ $44^{\prime} \mathrm{N}, 5^{\circ} 13^{\prime} \mathrm{E}, 19 . v i .2012$ (5 females); Rangen, $48^{\circ} 40^{\prime} \mathrm{N}, 7^{\circ}$ $28^{\prime} \mathrm{E}, 25 . v i .2015$ (1 female). Bulgaria: Muldava, $41^{\circ} 59^{\prime} \mathrm{N}$, $24^{\circ} 56^{\prime} \mathrm{E}, 21 . v i i i .2015$ (1 female); Topolovo, $41^{\circ} 54^{\prime} \mathrm{N}, 25^{\circ}$ $01^{\prime} \mathrm{E}, 21 . v i i i .2015$ (1 female). Kosovo: Stubel, $42^{\circ} 20^{\prime} \mathrm{N}, 21^{\circ}$ 27'E, 1.ix.2015 (1 female). The non-type material is deposited in the collection of the IPPTS under the accession number IPPT-CL-2017-00.

ZooBank registration: To comply with the regulations set out in article 8.5 of the amended 2012 version of the International Code of Zoological Nomenclature (ICZN) [33], details of the new species have been submitted to ZooBank. The Life Science Identifier (LSID) of the article is urn:lsid:zoobank.org:pub:0C1AA32E-9C07-402BBB58-7B5BFF72EA19. The LSID for the new name Culicoides bysta is urn:lsid:zoobank.org:act:BFB32DDDC44C-40D9-8427-EAF869F122C0.

Etymology: Named after a small village in south-eastern Slovakia, where the species was detected for the first time.

\section{Description}

Adult female. [Based on 20 paratypes; Figs. 5, 6a-c, and 7a-d.] Head: Eyes (Fig. 5b) bare, contiguous over a distance which can be estimated as approximately the diameter length between one and two adjacent facets, 34.8 (21.9-46.0, $n=20$ ). Antenna (Fig. 5c): sensilla coeloconica present on flagellomeres 1, 9-13 (respective 


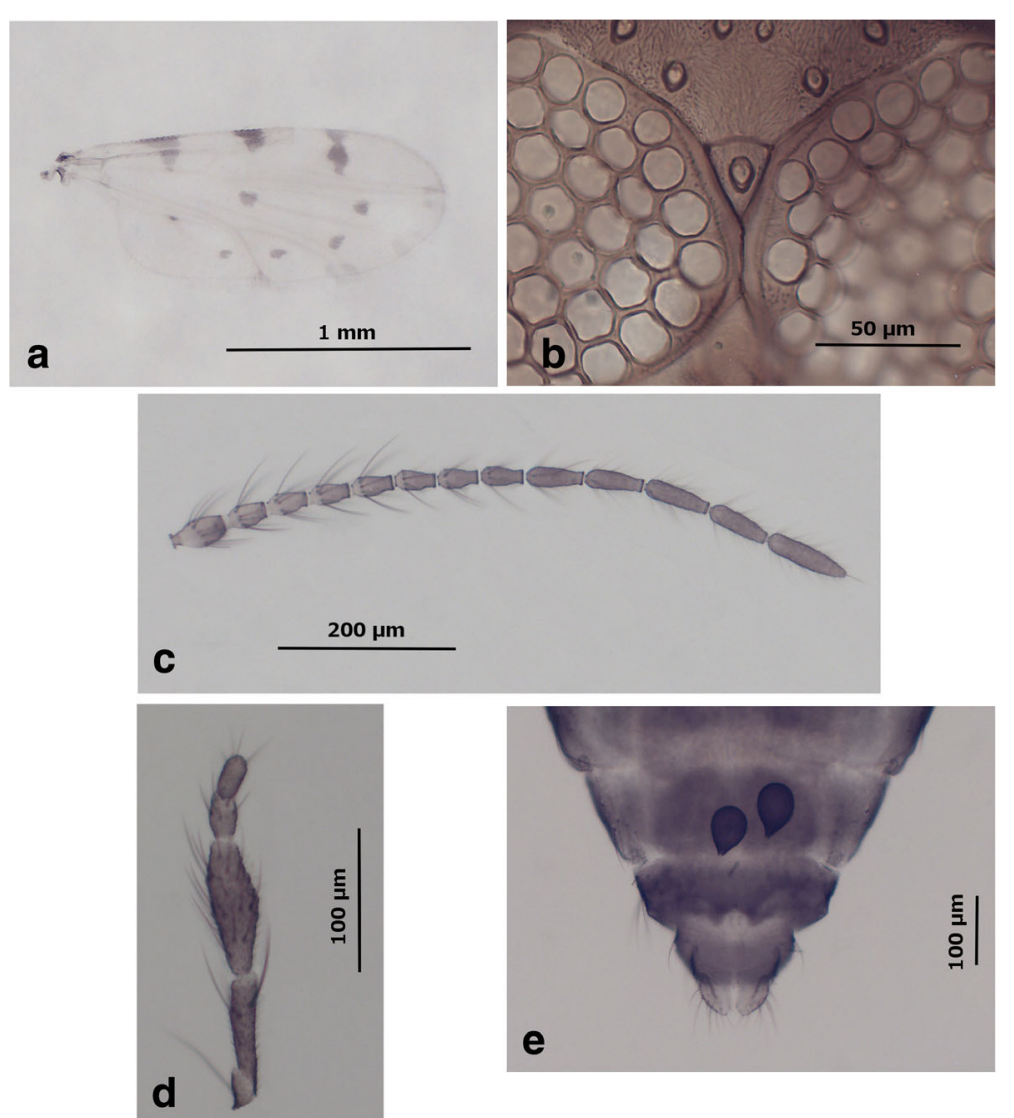

Fig. 5 Images of C. bysta n. sp. female. a Wing. b Eyes. c Antenna. d Palpus. e Last abdominal segments with spermathecae. Scale-bars: a, 1 mm; b, $50 \mu \mathrm{m} ; \mathbf{c}, 200 \mu \mathrm{m} ; \mathbf{d}, \mathbf{e}, 100 \mu \mathrm{m}$

sensilla numbers are presented in Table 3); blunt-tipped sensilla trichodea distributed as 2 long on flagellomere 1 , 2 long and 1 short on segments 2-8; AtR 1.50 (1.15$1.87, n=40)$; length of flagellomeres 1-8 347 (297-400, $n=33)$; total length of flagellum $719(647-792, n=22)$; antennal ratio $1.03(0.92-1.16, n=22)$; R11/10 given in Table 4; ratio of first flagellomere 1.64 (1.3-1.8, $n=25)$. Palpus (Fig. 5d) slender, palpal segment I with 1 long chaetica; segment II with 3.9 chaeticae; segment III slightly swollen, carrying 13.1 chaeticae, with multiple irregular pits sparse on segment; segment IV with 7 short chaeticae; segment $\mathrm{V}$ without chaetica but with 5 apical bristles $(n=10)$; length of segments I-V: $87.2(76-101)$ (I+ II), 90.6 (78-106), 34.9 (25-44) and 36.4 (32-44); total length 250 (216-287, $n=25)$; PR 2.7 (2.4-3.1, $n=$ 39) (proboscis length and $\mathrm{P} / \mathrm{H}$ ratio are presented in Table 4). Maxilla with $18(17-21, n=10)$ teeth; mandible with $14.36(12-16, n=33)$ teeth. Cibarial and pharyngeal armature absent. Thorax: Legs (Fig. 6a-c) brownish, with usually pale bands described hereafter. Foreleg: proximal part of femur slightly pale, fore-tarsus pale, spines on all tarsal segments absent; lengths of femur, tibia and tarsal segments: 417, 432, 226, 106, 69, 39 and $44(n=5)$; foreleg TR $2.1(n=5)$. Middle leg: knee and mid-tarsus pale, 2 spines present distally on first tarsal segments, 2 on second, 2 on third, 1 on fourth; lengths of femur, tibia and tarsal segments: 543, 548, 288, 110, 69, 43 and $48(n=5)$; middle leg TR $2.6(n=5)$. Hind leg: pale ring on proximal part of hind-tibia, tibial comb with $5.9(5-7, n=36)$ spines, spines on all tarsal segments absent; lengths of femur, tibia and tarsal segments: $515,524,273,146,81,47$ and $58(n=5)$; hind leg TR $1.9(n=5)$. Wing (Figs. 5a and $7 \mathrm{a}-\mathrm{d})$ : r3 pale with narrow dark hour-glass shape spot, incomplete, with posterior margin short, narrow, clearly not reaching M1 vein; cubital-anal fork pale $(n=58)$; dark spot in distal part of anal cell and an extra-dark spot present, smaller and close to the $\mathrm{CuA} 2$ vein, observed on only one wing for $17 \%$ of the specimens and on both wings for $52 \%$ of the specimens $(n=58)$; extra-dark spot rarely reaching CuA2 (2/58 wings) (Fig. 7c); sometimes, regular dark spot in anal cell absent (4/58 wings) (Fig. 7b); dark, rounded spot in distal part of $\mathrm{m} 2$ separated from the dark area on CuA1 $(n=58)$ (Fig. $7 \mathrm{a}-\mathrm{d})$ and the latter area rarely fused to the dark spot in $\mathrm{m} 2$ (3/58 wings); tips of the veins M1, M2, and CuA1 dark with 
Table 3 Distribution of sensilla coeloconica along the flagellomeres. Data are provided for females and males of C. bysta n. sp. and C. pulicaris from Slovakia (SK) and France (FR); no males of C. bysta n. sp. were observed and measured in France

\begin{tabular}{|c|c|c|c|c|c|c|c|c|c|c|c|c|c|c|}
\hline \multirow[t]{2}{*}{ Species } & \multirow[t]{2}{*}{ Country } & \multicolumn{13}{|c|}{ Flagellomere } \\
\hline & & 1 & 2 & 3 & 4 & 5 & 6 & 7 & 8 & 9 & 10 & 11 & 12 & 13 \\
\hline \multicolumn{15}{|l|}{ Female } \\
\hline C. bysta n. sp. & SK & $6(2-9)$ & 0 & 0 & 0 & 0 & 0 & 0 & 0 & $1.4(1-2)$ & $1.7(1-3)$ & $1.9(1-3)$ & $2.1(1-3)$ & $2(1-3)$ \\
\hline C. bysta n. sp. & $F R$ & $5.6(5-7)$ & 0 & 0 & 0 & 0 & 0 & 0 & 0 & $1.5(1-2)$ & $1.5(1-2)$ & $1.8(1-2)$ & $2(2-2)$ & $1.9(1-3)$ \\
\hline C. pulicaris & SK & $3.3(3-4)$ & 0 & 0 & 0 & 0 & 0 & 0 & 0 & $1.1(0-2)$ & $1.2(1-2)$ & 1 & $3.2(2-5)$ & $3.5(2-5)$ \\
\hline C. pulicaris & $F R$ & $4.7(4-5)$ & 0 & 0 & 0 & 0 & 0 & 0 & 0 & $1.1(1-1)$ & $1.3(1-2)$ & $1.4(1-3)$ & $2.3(2-3)$ & $2.8(2-3)$ \\
\hline \multicolumn{15}{|l|}{ Male } \\
\hline C. bysta n. sp. & SK & 2 & 0 & 0 & 0 & 0 & 0 & 0 & 0 & 0 & 0 & $1.2(1-2)$ & $2.6(2-3)$ & $2.9(3-4)$ \\
\hline C. pulicaris & SK & na & 0 & 0 & 0 & 0 & 0 & 0 & 0 & 0 & 0 & $1(0-2)$ & $4.2(1-7)$ & $5.3(2-11)$ \\
\hline C. pulicaris & $F R$ & na & 0 & 0 & 0 & 0 & 0 & 0 & 0 & 0 & 0 & $1(1-2)$ & $4.5(4-6)$ & $5(5-7)$ \\
\hline
\end{tabular}

sometimes centred by a pale spot in 71,31 , and $11 \%$, respectively $(n=56)$ (see Table 4 for wing measurements). Abdomen (Fig. 5e): first abdominal tergite with $10.8(6-14, n=26)$ hairs. Spermathecae: 2 functional and 1 rudimentary; functional spermathecae ovoid, with short narrow pigmented neck, moderately sclerotized, equal in size (see measurements in Table 4); parallel sclerotized ring present. Sclerotization surrounding oviduct narrow, slightly parallel.

Male. [Based on the holotype and 11 paratypes; Figs. 6d-f and 8.] Head: Eyes (Fig. 8c) bare, contiguous. Antenna (Fig. 8e, Table 3): sensilla coeloconica present on flagellomeres 1, 11-13 (Table 3); verticils of numerous sensilla chaetica from flagellomere 1 to 12 , flagellomere 13 with 5.4 sensilla basally including 1 regularly present in median part of flagellomere, 2 sensilla on flagellomere 12, none on basal part of flagellomere 13 and 1 sensilla apically; blunt-tipped sensilla trichodea not swollen, distribution: 1.9 long on flagellomere 1, 2 long, and 1 short on flagellomeres 2 to $4,1.1$ long and 1.1 short on flagellomere 5, 1 long and 1 short on 6 and 7, 1 long and 0.4 short on 8 and absence of trichodea on flagellomeres 9 to $13(n=16)$; lengths of flagellomeres 1-13: 111, 47, 44, 44, 43, 43, 42, 40, 40, 50, 116, 93 and $115(n=15)$; total length of antenna $828(n=14)$; AR: 0.6

Table 4 Measurements of the most important female body characters. The mean and the range of values (minimum-maximum) are given for each character with the exception of the data for C. boyi from Denmark (DK), taken from Nielsen et al. [23]. P/H ratio is given as the reverse of $\mathrm{H} / \mathrm{P}$ ratio

\begin{tabular}{|c|c|c|c|c|c|}
\hline Species & C. bysta n. sp. & C. bysta n. sp. & C. pulicaris & C. pulicaris & C. boyi \\
\hline Country & SK & $\mathrm{FR}$ & SK & $\mathrm{FR}$ & DK \\
\hline Wing length (mm) & $1.5(1.1-1.7)$ & $1.4(1.1-1.6)$ & $1.6(1.3-1.8)$ & $1.6(1.2-1.95)$ & $1.6^{\mathrm{a}}$ \\
\hline Wing ratio $L / W$ & $2.2(1.9-2.3)$ & $2.2(2.1-2.3)$ & $2.3(2.2-2.4)$ & $2.2(2.0-2.2)$ & \\
\hline Antennal ratio & $1.03(0.92-1.16)$ & $1.09(0.54-1.35)$ & $1.03(0.95-1.09)$ & $1.05(0.99-1.08)$ & $1.3^{\mathrm{a}}$ \\
\hline Ratio $\left(\right.$ R11/10) ${ }^{*}$ & $1.37(1.26-1.50)$ & $1.37(1.25-1.45)$ & $1.41(1.14-1.54)$ & $1.46(1.30-1.54)$ & \\
\hline$A t R^{* * *}$ & $1.5(1.15-1.87)$ & $1.5(1.2-1.8)$ & $1.77(1.56-2.08)$ & $1.7(1.5-1.8)$ & $1.5(1.3-1.7)$ \\
\hline Palpal ratio & $2.7(2.4-3.1)$ & $2.7(2.4-3.1)$ & $2.4(1.9-3.0)$ & $2.3(1.8-2.7)$ & $2.9^{\mathrm{a}}$ \\
\hline Proboscis lenght & $209(187.5-250)$ & $206(188-221)$ & $228(203-255)$ & $229(199-257)$ & $218(203-235)$ \\
\hline $\mathrm{P} / \mathrm{H}$ ratio ${ }^{* * *}$ & $0.8(0.7-0.8)$ & $0.8(0.7-0.8)$ & $0.8(0.8-0.9)$ & $0.9(0.8-0.9)$ & \\
\hline H/P ratio ${ }^{* * *}$ & $1.3(1.2-1.4)$ & $1.3(1.3-1.4)$ & $1.19(1.1-1.2)$ & $1.2(1.1-1.2)$ & $1.29^{\mathrm{a}}$ \\
\hline Spermatheca I length $(\mu \mathrm{m})$ & $71(51-81)$ & $67(49-76)$ & $79(71-90)$ & $71(65-79)$ & \\
\hline Spermatheca I width $(\mu \mathrm{m})$ & $51.6(46-58)$ & $52(48-59)$ & $53(47-64)$ & $51(47-61)$ & \\
\hline Spermatheca II length $(\mu \mathrm{m})$ & $67(53-78)$ & $67(56-74)$ & $64(62-64)$ & $69(58-76)$ & \\
\hline Spermatheca II width ( $\mu \mathrm{m})$ & $48.5(44-55)$ & $52(47-58)$ & 47 (39-58) & $49(45-54)$ & \\
\hline
\end{tabular}

Significant differences ( ${ }^{* *} P<0.001$ and $\left.{ }^{*} P<0.05\right)$ between $C$. bysta $\mathrm{n}$. sp. and $C$. pulicaris are indicated considering the cumulative data from Slovakia (SK) and France (FR). No differences within the species and between the countries, or between C. bysta n. sp. and C. boyi, were observed. Culicoides boyi and C. pulicaris were significantly different for the AtR ratio $(P<0.05)$

${ }^{\mathrm{a} D a t a}$ from Nielsen et al. [23] 


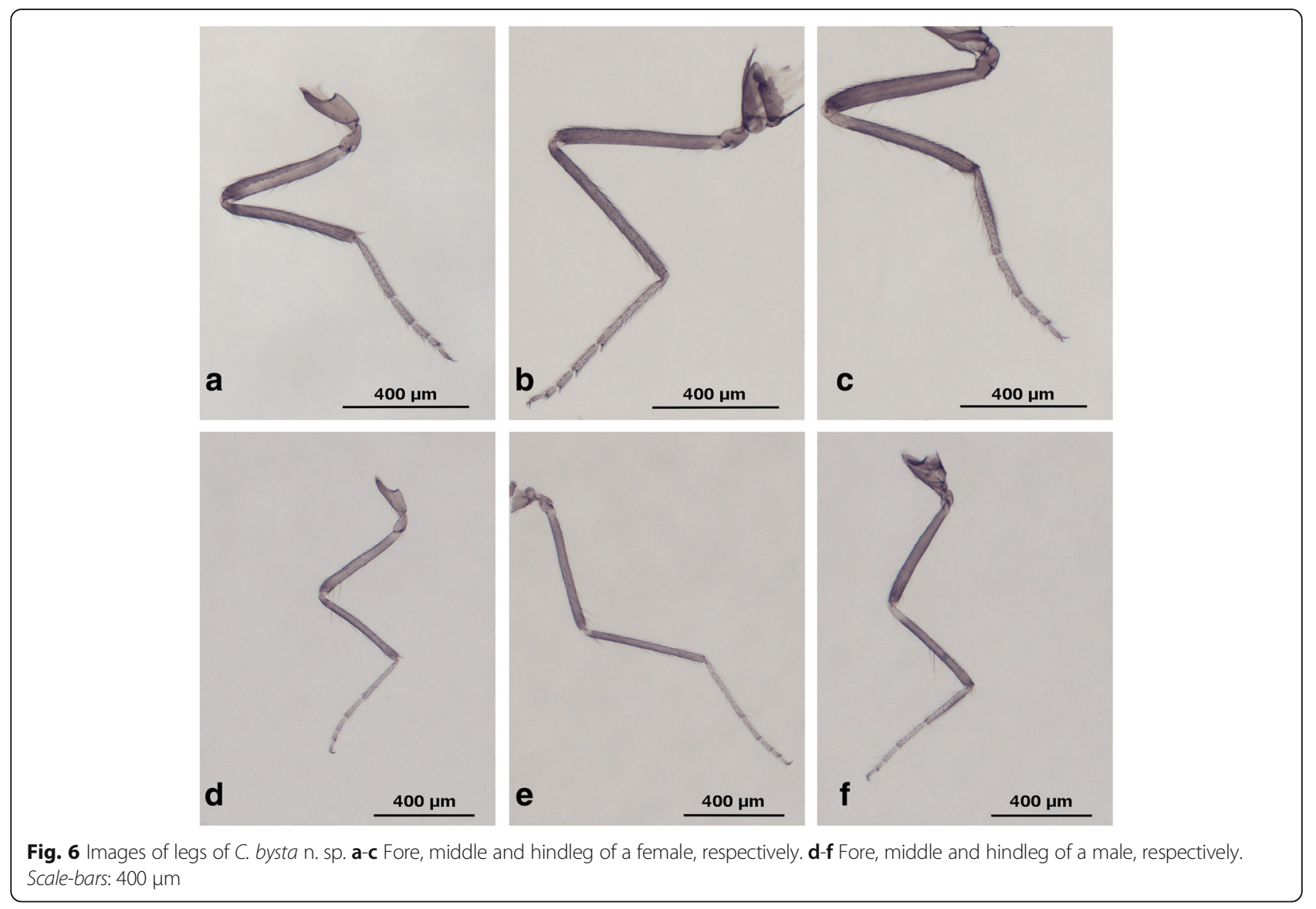

$(n=14)$; ratio between lengths of first long flagellomere and last short R11/10 =2.3 $(n=14)$. Palpus (Fig. $8 \mathrm{c}, \mathrm{d}$ ) slender, palpal segment I with 1 long chaetica, segment II with 4 short chaeticae, segment III slightly swollen, carrying 4.6 short chaeticae, with multiple irregular pits located in third apical part of segment, segment IV with 3 short chaeticae, segment $\mathrm{V}$ without chaetica but with 5 apical bristles $(n=9)$; lengths of segments I-V: 67 (I + II), 67, 33 and $38(n=17)$; total length $205(n=17)$; PR: $4.2(n=18) ; \mathrm{R} 3 / 1+2: 1.01 \quad(n=16)$. Maxilla with several teeth-like structures; mandible without teeth. Cibarial and pharyngeal armature absent. Thorax: Legs (Fig. 6d-f) brownish, with usually pale bands, as in females; foreleg lacking spines on all tarsal segments $(n=22)$; lengths of fore femur, tibia, and tarsal segments: $429,412,229,108,67,42$ and $44(n=4)$; foreleg TR $2.1(n=4)$; middle leg with 2 spines distally on first tarsal segments, 2 on second, 1.9 on third, 1 on fourth $(n=22)$, lengths of middle femur, tibia, and tarsal segments: 550, 525, 281, 118, 71, 42 and $42(n=4)$; middle leg TR: $2.4(n=4)$; hind leg with hindtibial comb with 6.1 spines, lacking spines on all tarsal segments $(n=22)$; lengths of hind femur, tibia and tarsal segments: 488,
493, 255, 151, 84, 45 and $46(n=4)$; hind leg TR: 1.7 $(n=4)$. Wing pattern (Fig. 8a) similar to females; wing length $\times$ width $1360 \times 460(n=9)$. Abdomen (Fig. 8b): First abdominal tergite with 12.3 lateral hairs $(n=15)$. Genitalia (Fig. 8f): Ninth sternite wide, with slight posteromedial indentation and sparse pubescence laterally; ventral membrane not spiculated; tergite 9 approximately as wide as long, with clear median cleft and long apicolateral processes (see measurements of apicolateral processes and related distances $\mathrm{Dt}$ and $\mathrm{Db}$ in Table 5); gonocoxite swollen in its basal part, middle part of internal edges lined with thick spines; ventral apodeme small, hook-shaped, dorsal apodeme cylindrical, robust; gonostylus barely longer than gonocoxite and twice as wide at basal edge as at apex, width of basal part reduced abruptly from $1 / 3$ length to a parallel shape till the last $2 / 3$ of gonostylus. Aedeagus (Fig. 8f) Y-shaped with round, short tip and long lateral arms, straight and curved at base; moderately sclerotized arch present in proximal part, where lateral arms join body of aedeagus. Parameres (Fig. 8f) separated, slender, becoming gradually very thin from proximal to distal part, tip of parameres terminating in fine pubescence. 

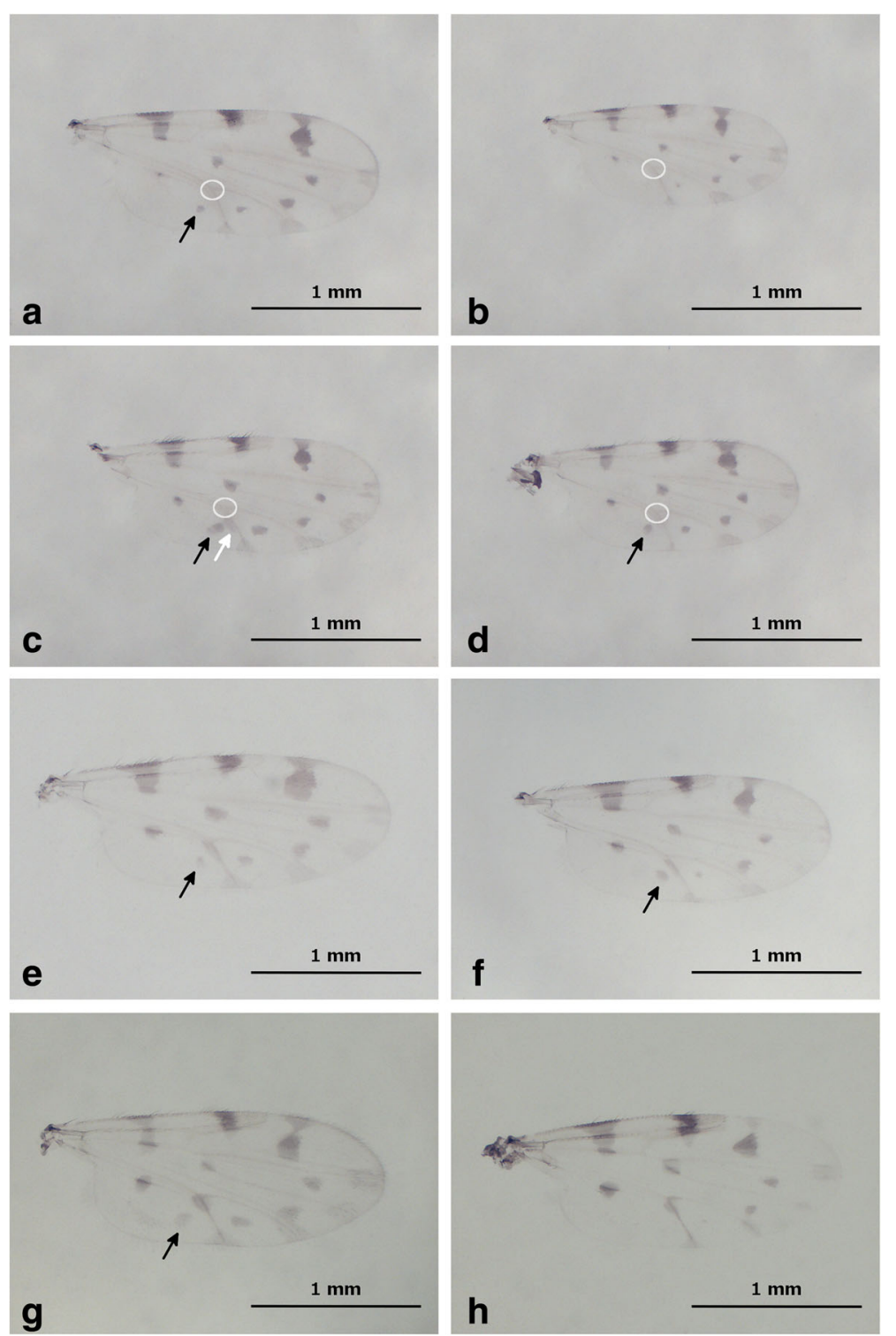

Fig. 7 Images showing wing pattern variations within the C. bysta n. sp., C. boyi and C. pulicaris. a-d C. bysta n. sp. e-f C. boyi. g-h C. pulicaris. Light circles show the pale cubital-anal fork while the circle absence means a dark fork. Black and white arrows indicate the regular and the extra dark spot in the anal cell, respectively. Scale-bars: $1 \mathrm{~mm}$

\section{Immatures. Unknown.}

\section{Differential diagnosis}

The combination of three characters of the wing pattern in females is discriminant to separate C. bysta n. sp. from C. pulicaris and C. boyi: (i) absence of a dark spot on the cubital-anal fork, (ii) a dark rounded spot in the distal part of $\mathrm{m} 2$, separated from the dark area on the $\mathrm{CuA} 1$ and, (iii) an incomplete and narrow hour-glass shape dark spot in $\mathrm{r} 3$ with the posterior margin short and narrow (Figs. 5a and 7a-d). In addition, several quantitative characters revealed significant differences, the most important being the Dios-ts and the ratio
Dios-ts/Lios on the eyes (Table 6); the AtR ratio for $C$. bysta n. sp. is significantly smaller than that in C. pulicaris $[1.50(n=52)$ vs $1.77(n=17)$; see Table 4$]$; the $\mathrm{P} / \mathrm{H}$ ratio for C. bysta $\mathrm{n}$. sp. is significantly smaller than that in C. pulicaris [0.77 $(n=26)$ vs $0.85(n=10)$; see Table 4]; the ratios of the first flagellomere are varied among $C$. pulicaris, C. boyi and C. bysta n. sp.: $1.52 \pm 0.07$ [22], $1.78 \pm 0.07$ [22] , and $1.62 \pm 0.1(n=33)$, respectively.

Considering the lack of description of the male in $C$. boyi, the following diagnosis comments on the male of C. bysta are focused on comparison with C. pulicaris. The wing pattern of C. bysta $\mathrm{n}$. sp. is similar to that in the female and may be used with confidence for the 

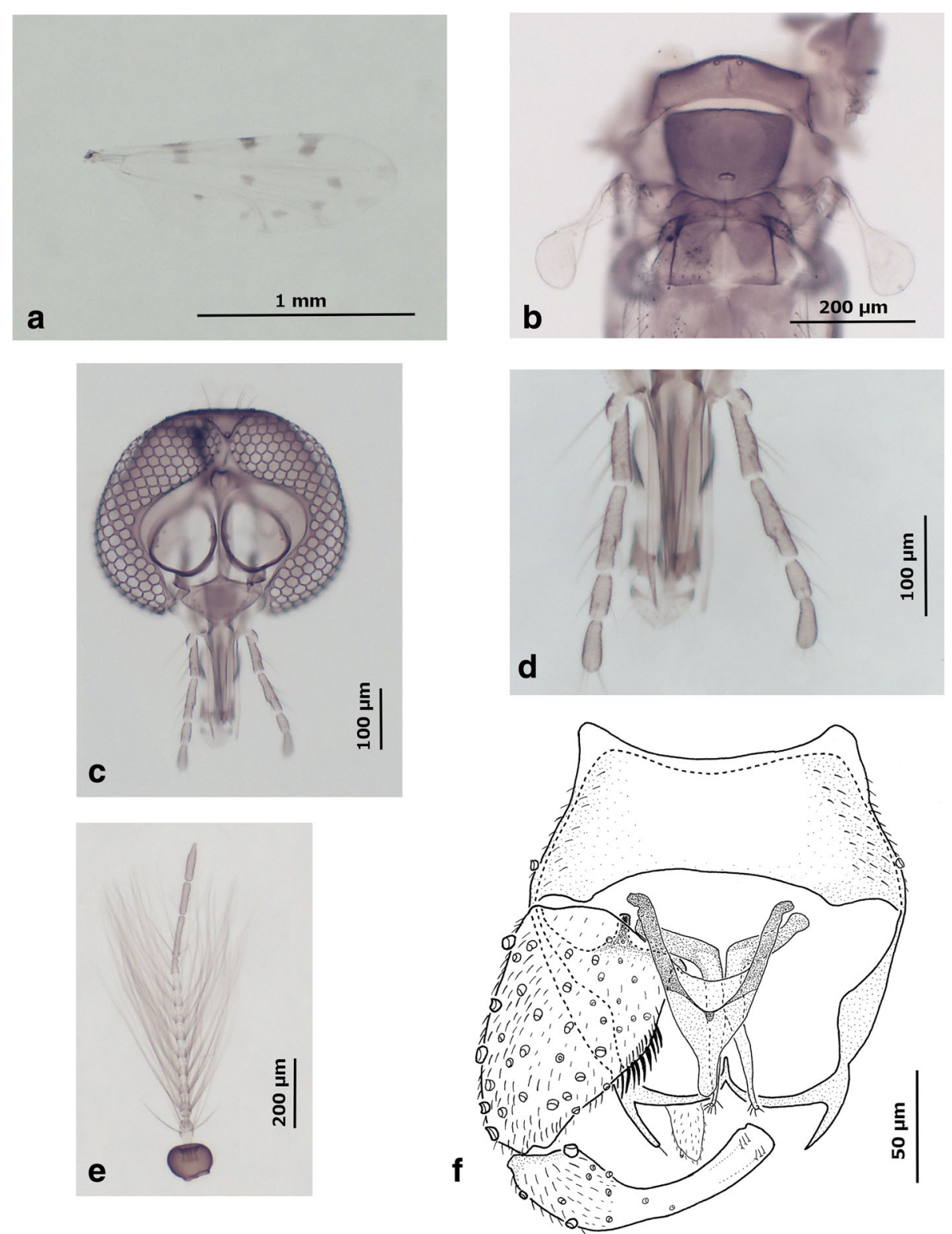

Fig. 8 Illustrations of C. bysta n. sp. male. a Wing. b Scutellum, scutum and first abdominal segment. c Head. d Palpal segments. e Antenna. f Genitalia. Scale-bars: a, 1 mm; b, e, $200 \mu \mathrm{m} ; \mathbf{c}, \mathbf{d}, 100 \mu \mathrm{m} ; \mathbf{f}, 50 \mu \mathrm{m}$

Table 5 Measurements of male genitalia in micrometres presented as the mean followed by the range in parentheses

\begin{tabular}{lllllll}
\hline & N1 & Lap & Wap & N2 & Dt & Db \\
\hline C. bysta n. sp. $^{\text {C. pulicaris }}{ }^{\mathrm{a}}$ & 24 & $22(16-28)^{* * *}$ & $5.7(3.6-7.2)$ & 12 & $65(54-72)^{* *}$ & $77(65-89)^{* * *}$ \\
C. pulicaris SK & 34 & $15(8.5-22)^{* * *}$ & $4.9(3.6-7.6$ & 16 & $55(45-67)^{* *}$ & $59(38-74)^{* * *}$ \\
C. pulicaris FR & 24 & $14(8.5-22)$ & $5.3(3.6-7.6)$ & 11 & $56(45-67)$ & $62(38-74)$ \\
\hline
\end{tabular}

Abbreviations: Lap length of the apical processus, Wap width of the apical processus, Dt distance between the tips of the apical processes, $D b$ distance between the bases of apical processes, N1and N2 numbers of observations for Lap/Wap and Dt/Db, respectively

Significant differences $\left({ }^{* * *} P<0.001\right.$ and $\left.{ }^{* *} P<0.01\right)$ between $C$. bysta $\mathrm{n}$. sp. and C. pulicaris are indicated considering the cumulative data from Slovakia (SK) and France (FR); no significant differences were found between geographical populations of C. pulicaris

${ }^{\mathrm{a}}$ The data from C. pulicaris were considered as a whole (C. pulicaris) or separately, regarding the origin in Slovakia (C. pulicaris SK) and France (C. pulicaris FR) 
Table 6 Measurements of female eyes in micrometres. The mean and the range of values (minimum-maximum) are given for each character. Means indicated with the same letter (a-d) are not significantly different

\begin{tabular}{llllll}
\hline Species & $n$ & Lios & Dios-ts & Lts & Dios-ts/Lios \\
\hline C. bysta n. sp. & 18 & $30.5(22.3-41.1)$ & $25.9(19.6-32)^{\mathrm{a}}$ & $21.3(14.8-27)$ & $0.9(0.5-1.2)^{\mathrm{c}}$ \\
C. boyi & 5 & $25.5(20.0-34.5)$ & $27.6(26.4-29.7)^{\mathrm{a}}$ & $19.4(17.1-22.6)$ & $1.1(0.8-1.5)^{\mathrm{d}}$ \\
C. pulicaris & 4 & $29.9(23-32.2)$ & $21.3(20.7-23)^{\mathrm{b}}$ & $19.0(16.1-23)$ & $0.7(0.6-0.9)^{\mathrm{cd}}$ \\
\hline
\end{tabular}

Abbreviations: Lios length of the inter-ocular suture of the joined eyes, Dios-ts distance between the inter-ocular suture and the transverse suture above the first inter-ocular seta, Lts length of the transverse suture, Dios-ts/Lios ratio of the above mentioned characters measured

identification of males. In addition, the measurement of $\mathrm{Db}$ on the ninth tergite can discriminate $C$. bysta n. sp. from $C$. pulicaris with $77(65-89, n=12) \mu \mathrm{m}$ and $59(38-74, n=8)$ $\mu \mathrm{m}$, respectively, even though a small overlap exists there (Table 5). Differences are also observed on Lap and Dt but the overlap of measures is wider than with $\mathrm{Db}$.

\section{Culicoides (Culicoides) boyi Nielsen, Kristensen \& Pape, 2015}

Syn. Culicoides dk1 of Lassen et al. (2012) [18]

Type-material examined: Denmark, Himmerland, Aalestrup, 56 40'5.13"N, 09²8'53.53"E, 9.ix.2008 (Paratype D, female), 22.vii.2009 (Paratypes E, F, 2 females); Himmerland, Nibe, 56 $54^{\prime} 21.05^{\prime \prime N}, 09^{\circ} 37^{\prime} 23.90^{\prime \prime E}$ 9.vii.2008 (Paratype G, female); Mors, Nykøbing Mors, $56^{\circ}$ $53^{\prime} 55.39^{\prime \prime N}, 08^{\circ} 48^{\prime} 41.65 " \mathrm{E}, 9 . v i i .2008$ (Paratype H, female). Non-type material examined: Denmark, Zealand, Rønnede, $55^{\circ} 15^{\prime} \mathrm{N}, 12^{\circ} 01^{\prime} \mathrm{E}, 24-26 . v i .2015$ (2 females).

Distribution: Denmark and recorded to France at the time of submission [22, 23, 34].

\section{Remarks}

We evaluated the variations of the wing pattern of $C$. boyi and hereafter we present the summary of our observations (Fig. 7e, f): cubital-anal fork dark extended to at least a third of the vein $(n=14)$; a dark spot present in the distal part of the anal cell; a dark rounded spot present in the distal part of $\mathrm{m} 2$, usually connected from the dark area on the CuA1 $(n=14)$ with the dark spot and area rarely separated (4/14 wings); tips of the veins M1, M2, and CuA1 dark, with sometimes a slightly pale spot in M1 (10/14 wings). Based on these observations, we suggest to use first the wing pattern to discriminate between C. bysta n. sp. and C. boyi (see above).

\section{Discussion}

The phylogenetic and morphological differences presented here justify the distinct status of C. bysta n. sp. within the Pulicaris group. The maximum interspecific genetic distance between the new species and $C$. boyi is low (7.6\%), although greater than between the C. selandicus and the C. kalix (5.9\%) [23]. For the most part, cox 1 distances between species are usually found to be higher than $10 \%[15,18,19,23,35]$. Thus, within the subgenus Culicoides, the lowest pairwise genetic distance was $12 \%$ between $C$. fagineus $\mathrm{F} 1$ and $C$. subfagineus (s.s.) in [15]. Moreover, the comparison of five closely related species within the subgenus Avaritia showed even lower genetic distance of $9.5 \%$ between C. bolitinos Meiswinkel, 1989 and C. tutti-frutti Meiswinkel, Cornet \& Dyce, 2003 [34]. Although the genetic distance recorded between C. bysta n. sp. and C. boyi is low, the frequency distribution of pairwise genetic distances evidence a barcode gap between the intra- and the interspecific distances (Fig. 4). A similar graph was plotted to confirm the hypothesis of $C$. scoticus being a race of $C$. obsoletus [36]. As for the intraspecific distances, Pagès et al. [15] presented very low values (smaller than $0.6 \%$ ) for all clades analyzed, including C. newsteadi N1. Moreover, the added specimen of $C$. newsteadi $\mathrm{N} 1$ sequenced in the previous study [19] exhibits a higher intraspecific genetic distance of $3.4 \%$ within the latter species. Thus the four existing and highly supported clades within C. newsteadi (sensu lato) indicate a clear need of an in-depth revision.

Genetically and morphologically, C. boyi is the closest species to C. bysta n. sp. and both exhibit morphological similarities to C. pulicaris. Culicoides bysta n. sp. can be distinguished from C. boyi and C. pulicaris by the combination of the following characters on the wing pattern: (i) the absence of a dark spot on the cubital-anal fork; (ii) the presence of a dark rounded spot in the distal part of $\mathrm{m} 2$ separated from the dark area on the $\mathrm{CuA} 1$ vein; and (iii) an incomplete and narrow hour-glass shape dark spot in $\mathrm{r} 3$ with short and narrow posterior margin. In addition to the ratio of the first flagellomere, the two newly evaluated characters are the most important for discrimination. Thus the females of C. bysta n. sp. possess a Dios-ts/Lios ratio significantly lower than that in C. boyi and higher than that in C. pulicaris. For males, $\mathrm{Db}$ measurements allow accurate discrimination between C. bysta n. sp. and C. pulicaris. Nevertheless, the male of $C$. boyi remains undescribed and the usefulness of $\mathrm{Db}$ as the discriminating character for males of $C$. boyi and C. bysta n. sp. should be investigated in future.

Detected in Slovakia, C. bysta n. sp. was recorded in areas from the eastern to the western parts of the country. This species appeared to be present in various environments such as farms with domestic ruminants or horses, in forests hosting game animals, as well as in 
zoological gardens and family houses with domestic animals and poultry. First recorded in Slovakia, C. bysta n. sp. was afterwards identified in France. This species appeared to not be as rare because the specimens were found in various localities in the north-east of France. During the preparation of the present description, additional specimens were also recorded in Bulgaria and Kosovo, indicating that C. bysta n. sp. may be widespread in Europe. As C. pulicaris is known to exhibit morphological variation [12-14], special attention should be paid in future studies on the Pulicaris group. For instance, at the time of submission of the present manuscript, an article was published with a new record of C. boyi for the fauna of France [34]. In the latter study, the genetic data fit perfectly with the data for $C$. boyi from Denmark, but morphologically the specimens from France exhibited variation. However, the combination of the above mentioned three characters may still be used for the accurate identification.

Several species morphologically similar to C. pulicaris and thus close to the newly described C. bysta n. sp. were considered to be competent vectors for BTV and SBV transmissions. As for BTV, C. pulicaris and C. lupicaris were involved in the transmission by virus isolation and RT-PCR, respectively [2, 7]. While both studies processed the pools of specimens identified by morphology, eventual presence of cryptic species within those pools remains possible. Similarly, a recent study implicated C. punctatus in the transmission of SBV by RTPCR from pools of morphologically identified specimens [11]. To avoid the doubt which can be raised afterwards, studies dealing with Culicoides spp. should include molecular controls for the identification, such as (i) use of the diagnostic PCR tool for cryptic species within the subgenus Culicoides, for example [15], or (ii) sequencing of the barcode cox 1 region as in a recent study [37] where $\operatorname{cox} 1$ was used to confirm the identification of specimens orally exposed to SBV. In the light of the increasing number of studies describing Culicoides spp. diversity, such as those providing evidence for the presence of cryptic species complexes and descriptions of new species, all studies using these midges as biological material should associate the molecular ID to their morphological ID. While none of the recent cryptic or new species have been involved in the arbovirus transmission so far, future studies focused on the evaluation of the role of Culicoides spp. in the transmission, taking into account the entire recently described diversity, may lead to overhaul the current knowledge of Culicoides transmitting diseases.

\section{Conclusions}

We described here C. bysta n. sp. as a new species belonging to the Pulicaris group of the subgenus
Culicoides. This species is closely related to the recently described C. boyi and to C. pulicaris. The phylogenetic analyses based on cox 1 and the morphological differences justify $C$. bysta $\mathrm{n}$. sp. as a distinct species. Female specimens of this new species described here can be distinguished by the wing pattern and by the ratio between two sutures on the joined eyes. This latter morphological character evaluated here for the first time, and the characters on the ninth tergite for males, are promising for species discrimination within the Pulicaris group. However, male of C. boyi remain unknown and comparison of males within the Pulicaris group requires further studies. The vector potential of the recently described species C. boyi and C.bysta n. sp. to transmit arboviruses, such as BTV and SBV, is unknown. The published data on vector implication of C. pulicaris in BTV transmission acquired prior the description of the two recently described species, $C$. boyi and C. bysta n. sp., should be re-evaluated in future.

\section{Abbreviations}

BTV: Bluetongue virus; CDC: Centers for Disease Control; cox1: Cytochrome coxidase subunit 1; IPPTS: Institut de Parasitologie et de Pathologie Tropicale de Strasbourg; RT-PCR: Reverse transcriptase PCR; SBV: Schmallenberg virus

\section{Acknowledgements}

The authors are very grateful to Søren Achim Nielsen and to Thomas Pape for useful exchange and lending the type-material of $C$. boyi deposited at the Natural History Museum of Denmark, University of Copenhagen (ZMUC). Samples from Bulgaria, Kosovo, and Denmark were collected under the VectorNet, the European network for sharing the data on the geographical distribution of arthropod vectors, transmitting human and animal disease agents (framework contract OC/EFSA/AHAW/2013/02-FWC1) funded by the European Food Safety Authority (EFSA) and the European Centre for Disease prevention and Control (ECDC). We are very grateful to the people involved in the collection of the above mentioned samples: B. Alten, N. Ayhan, D. Baymak, R. Bødker, V. Dvorak, C. Grønlund Clausen, K. Hlavackova, I. Katerinova, O. Mikov, Y. Ozbel, J. Risueno, P. Sumova, S. Tchakarova and P. Volf.

\section{Funding}

The research was supported by grant VEGA No. 1/0080/15, the basic research was provided by the National Referential Laboratory for Pesticides of the University of Veterinary Medicine and Pharmacy in Košice, and execution of the project "Centre of Excellence for Parasitology" (ITMS code: 26220120022) for the support of the operational program for the research and development which is funded by the European Regional Development Fund.

\section{Availability of data and materials}

The datasets supporting the article are included in the article. The type-material was deposited in IPPTS, UVLF and SNM under accession numbers IPPT-CL-201701 to IPPT-CL-2017-11, UVLF-CL-2017-01 to UVLF-CL-2017-11 and SZ10896 to SZ10905, respectively. Sequences for C. bysta $n$. sp. were submitted to the GenBank database under accession numbers KY436038-KY436054 and for C. boyi under accession numbers KY436055 and KY436056.

\section{Authors' contributions}

AK, AS and BM initiated the study; AS collected and identified the specimens from Slovakia; AS and BM measured the specimens and wrote the morphological description; BM carried out and drew up the molecular part; AS and BM drafted the manuscript. All authors read and approved the final manuscript.

Competing interests

The authors declare that they have no competing interests. 


\section{Consent for publication}

Not applicable.

\section{Ethics approval and consent to participate}

Not applicable.

\section{Publisher's Note}

Springer Nature remains neutral with regard to jurisdictional claims in published maps and institutional affiliations.

\section{Author details}

'Department of Parasitology, University of Veterinary Medicine and Pharmacy in Košice, Komenského 73, SK-04181 Košice, Slovak Republic. ${ }^{2}$ Medicine Faculty, Institute of Parasitology and Tropical Pathology (IPPTS), EA7292, 3 rue Koeberlé, F-67000 Strasbourg, France. ${ }^{3}$ Laboratoire de Parasitologie et de Mycologie Médicale, Hôpitaux Universitaires de Strasbourg, F-67000 Strasbourg, France.

Received: 28 October 2016 Accepted: 12 May 2017

\section{Published online: 02 June 2017}

\section{References}

1. Borkent A. World species of biting midges (Diptera: Ceratopogonidae). Research Associate of the Royal British Columbia Museum, Canada, Last Updated: February 28, 2012, 234 pp. http://wwx.inhs.illinois.edu/files/8413/ 4219/9566/CeratopogonidaeCatalog.pdf. Accessed 17 May 2017

2. Caracappa S, Torina A, Guercio A, Vitale F, Calabro A, Purpari G, et al. Identification of a novel bluetongue virus vector species of Culicoides in Sicily. Vet Rec. 2003;153:71-4

3. Dijkstra E, van der Ven IJ, Meiswinkel R, Holzel DR, Van Rijn PA. Culicoides chiopterus as a potential vector of bluetongue virus in Europe. Vet Rec. 2008;162:422.

4. De Liberato C, Purse BV, Goffredo M, Scholl F, Scaramozzino P. Geographical and seasonal distribution of bluetongue virus vector, Culicoides imicola, in central Italy. Med Vet Entomol. 2003;17:388-94.

5. Meiswinkel R, van Rijn P, Leijs P, Goffredo M. Potential new Culicoides vector of bluetongue virus in northern Europe. Vet Rec. 2007;161:564-5.

6. Mellor PS, Wittmann EJ. Bluetongue virus in the Mediterranean Basin 19982001. Vet J. 2002;164:20-37.

7. Romon P, Higuera M, Delecolle JC, Baldet T, Aduriz G, Goldarazena A. Phenology and attraction of potential Culicoides vectors of bluetongue virus in Basque Country (northern Spain). Vet Parasitol. 2012;186:415-24.

8. Savini G, Goffredo M, Monaco F, Di Gennaro A, de Santis P, Meiswinkel R, et al. The isolation of bluetongue virus from field populations of the Obsoletus Complex in central Italy. Vet Ital. 2004;40:286-91.

9. Savini G, Goffredo M, Monaco F, Di Gennaro A, Cafiero MA, Baldi L, et al. Bluetongue virus isolations from midges belonging to the Obsoletus complex (Culicoides, Diptera: Ceratopogonidae) in Italy. Vet Rec. 2005:157:133-9.

10. Vanbinst T, Vandenbussche F, Vandemeulebroucke E, De Leeuw I, Deblauwe I, De Deken G, et al. Bluetongue virus detection by real-time RT-PCR in Culicoides captured during the 2006 epizootic in Belgium and development of an internal control. Transbound Emerg Dis. 2009;56:170-7.

11. Larska M, Lechowski L, Grochowska M, Żmudziński JF. Detection of the Schmallenberg virus in nulliparous Culicoides obsoletus/scoticus complex and C. punctatus - the possibility of transovarial virus transmission in the midge population and of a new vector. Vet Microbiol. 2013;166:467-73.

12. Meiswinkel R, Gomulski LM, Delécolle JC, Goffredo M, Gasperi G. The taxonomy of Culicoides vector complexes - unfinished business. Vet Ital. 2004:40:151-9.

13. Campbell JA, Pelham-Clinton EC. A taxonomic review of the British species of Culicoides Latreille (Diptera: Ceratopogonidae). Proc R Soc Edin B. 1960:68:181-302

14. Kremer M. Contribution à l'étude du genre Culicoides Latreille particulièrement en France. Lechevalier $\mathrm{P}$, editor. Paris: Encyclopédie Entomologique Série A; 1965

15. Pagès N, Munoz-Munoz F, Talavera S, Sarto V, Lorca C, Nunez Jl. Identification of cryptic species of Culicoides (Diptera: Ceratopogonidae) in the subgenus Culicoides and development of species-specific PCR assays based on barcode regions. Vet Parasitol. 2009;165:298-310.
16. Wenk CE, Kaufmann C, Schaffner F, Mathis A. Molecular characterization of Swiss Ceratopogonidae (Diptera) and evaluation of real-time PCR assays for the identification of Culicoides biting midges. Vet Parasitol. 2012;184:258-66.

17. Ander $\mathrm{M}$, Troell $\mathrm{K}$, Chirico J. Barcoding of biting midges in the genus Culicoides: a tool for species determination. Med Vet Entomol. 2013;27:323-31.

18. Lassen SB, Nielsen SA, Skovgard H, Kristensen M. Molecular differentiation of Culicoides biting midges (Diptera: Ceratopogonidae) from the subgenus Culicoides Latreille in Denmark. Parasitol Res. 2012;110:1765-71.

19. Sarvašová A, Kočišová A, Halán M, Delécolle J-C, Mathieu B. Morphological and molecular analysis of the genus Culicoides (Diptera: Ceratopogonidae) in Slovakia with five new records. Zootaxa. 2014:3872:541-60.

20. Gomulski LM, Meiswinkel R, Delécolle JC, Goffredo M, Gasperi G. Phylogeny of the subgenus Culicoides and related species in Italy, inferred from internal transcribed spacer 2 ribosomal DNA sequences. Med Vet Entomol. 2006;20:229-38.

21. Ramilo D, Garros C, Mathieu B, Benedet C, Allène X, Silva E, et al. Description of Culicoides paradoxalis sp. nov. from France and Portugal (Diptera: Ceratopogonidae). Zootaxa. 2013;3745:243-56.

22. Nielsen SA, Kristensen M, Pape T. Three new Scandinavian species of Culicoides (Culicoides): C. boyi sp. nov., C. selandicus sp. nov. and C. kalix sp. nov. (Diptera: Ceratopogonidae). Biodivers Data J. 2015;3:e5823.

23. Nielsen SA, Kristensen M. Delineation of Culicoides species by morphology and barcode exemplified by three new species of the subgenus Culicoides (Diptera: Ceratopogonidae) from Scandinavia. Parasit Vectors. 2015;8:151.

24. Mathieu B, Cêtre-Sossah C, Garros C, Chavernac D, Balenghien T, Carpenter $\mathrm{S}$, et al. Development and validation of IIKC: an interactive identification key for Culicoides (Diptera: Ceratopogonidae) females from the Western Palaearctic region. Parasit Vectors. 2012;5:137.

25. Meiswinkel R. Afrotropical Culicoides: A redescription of C. (Avaritia) imicola Kieffer, 1913 (Diptera: Ceratopogonidae) with description of the closely allied C. (A.) bolitinos sp. nov. reared from the dung of the African buffalo, blue wildebeest and cattle in South Africa. Onderstepoort J Vet Res. 1989;56:23-39.

26. R Development Core Team, R: A Language and Environment for Statistical Computing. Vienna, Austria: the R Foundation for Statistical Computing. 2011, ISBN: 3-900051-07-0. Available online at http://www.R-project.org/.

27. Dallas JF, Cruickshank RH, Linton YM, Nolan DV, Patakakis M, Braverman Y, et al. Phylogenetic status and matrilineal structure of the biting midge, Culicoides imicola, in Portugal, Rhodes and Israel. Med Vet Entomol. 2003;17:379-87.

28. Folmer O, Black M, Hoeh W, Lutz R, Vrijenhoek R. DNA primers for amplification of mitochondrial cytochrome c oxidase subunit I from diverse metazoan invertebrates. Mol Mar Biol Biotechnol. 1994:3·294-9.

29. Thompson JD, Higgins DG, Gibson TJ. CLUSTAL W: improving the sensitivity of progressive multiple sequence alignment through sequence weighting, position-specific gap penalties and weight matrix choice. Nucleic Acids Res. 1994:22:4673-80.

30. Tamura K, Stecher G, Peterson D, Filipski A, Kumar S. MEGA6: Molecular Evolutionary Genetics Analysis version 6.0. Mol Biol Evol. 2013;30:2725-9.

31. Darriba D, Taboada GL, Doallo R, Posada D. jModelTest 2: more models, new heuristics and parallel computing. Nat Methods. 2012;9:772.

32. Ronquist F, Huelsenbeck JP. MrBayes 3: Bayesian phylogenetic inference under mixed models. Bioinformatics. 2003;19:1572-4.

33. International Commission on Zoological Nomenclature. Amendment of articles 8, 9, 10, 21 and 78 of the International Code of Zoological Nomenclature to expand and refine methods of publication. Zookeys. 2012;219:1-10.

34. Augot D, Hadj-Henni L, Millot C, Lehrter V, Cousinat M, Depaquit J. First report of Culicoides boyi (Diptera: Ceratopogonidae) in France. Ann Société Entomol Fr NS. 2016:0:1-8.

35. Linton YM, Mordue Luntz AJ, Cruickshank RH, Meiswinkel R, Mellor PS, Dallas JF. Phylogenetic analysis of the mitochondrial cytochrome oxidase subunit I gene of five species of the Culicoides imicola species complex. Med Vet Entomol. 2002;16:139-46.

36. Garros C, Mathieu B, Balenghien T, Cetre-Sossah C, Delécolle JC. Suggesting synonymies? Comments on Kiehl et al. (2009) "The European vectors of Bluetongue virus: are there species complexes, single species or races in Culicoides obsoletus and C. pulicaris detectable by sequencing ITS-1, ITS-2 and 18S-rDNA? Parasitol Res. 2010;107:731-4.

37. Balenghien $T$, Pagès $N$, Goffredo $M$, Carpenter $S$, Augot $D$, Jacquier $E$, et al. The emergence of Schmallenberg virus across Culicoides communities and ecosystems in Europe. Prev Vet Med. 2014;116:360-9. 